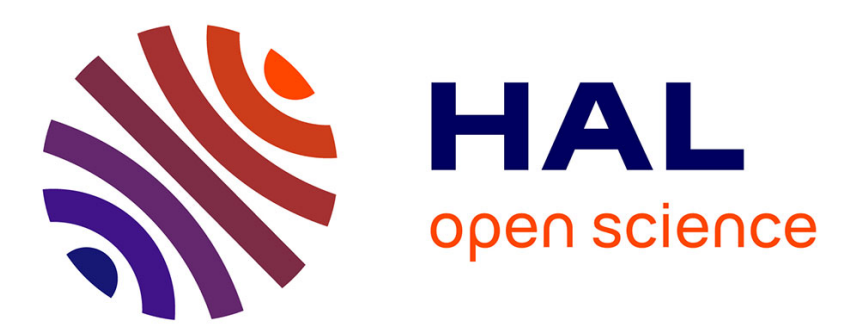

\title{
A methodological framework to analyse coping based on the testimony of the Director of the Fukushima Dai Ichi nuclear power plant
}

\author{
Aissame Afrouss, Aurélien Portelli, Franck Guarnieri
}

\section{- To cite this version:}

Aissame Afrouss, Aurélien Portelli, Franck Guarnieri. A methodological framework to analyse coping based on the testimony of the Director of the Fukushima Dai Ichi nuclear power plant. ESREL 2016, Sep 2016, Glasgow, United Kingdom. pp.614-620 - ISBN 978-1-138-02997-2. hal-01377036

HAL Id: hal-01377036

https://hal-mines-paristech.archives-ouvertes.fr/hal-01377036

Submitted on 6 Oct 2016

HAL is a multi-disciplinary open access archive for the deposit and dissemination of scientific research documents, whether they are published or not. The documents may come from teaching and research institutions in France or abroad, or from public or private research centers.
L'archive ouverte pluridisciplinaire HAL, est destinée au dépôt et à la diffusion de documents scientifiques de niveau recherche, publiés ou non, émanant des établissements d'enseignement et de recherche français ou étrangers, des laboratoires publics ou privés. 


\title{
A methodological framework to analyse coping based on the testimony of the Director the Fukushima Dai Ichi nuclear power plant
}

\author{
A. Afrouss ${ }^{1}$, A. Portelli ${ }^{1 \& 2} \&$ F. Guarnieri ${ }^{1}$ \\ ${ }^{1}$ CRC - MINES ParisTech, Sophia Antipolis, France \\ ${ }^{2}$ ESAIP, Grasse, France
}

\begin{abstract}
The Investigation Committee on the Accident at the Fukushima Nuclear Power Stations established by the Japanese government received testimony from Masao Yoshida, the Fukushima Dai Ichi plant's Director. During the hearing, Yoshida recounted the events he experienced between 11 and 15 March 2011 (Guarnieri et al., 2015; Guarnieri et al., 2016). He appears as a character in a narrative that describes the extreme situation that he and his workers faced at the plant. This testimony is an unprecedented source of knowledge, as it is the first time a first-hand account from a key manager in a nuclear accident has been made public. The transcript is an opportunity to undertake an analysis of Yoshida's selfrepresentation and examine the extreme situation through his eyes (Afrouss and Portelli, 2016). The analysis must also challenge classical explanations of the behaviour of collectives of engineers faced with a nuclear accident. This study requires a qualitative approach of Yoshida's testimony. This article outlines the methodological steps and precautions to be followed for such an analysis. It begins with a definition of coping and highlights its relevance to the Fukushima Dai Ichi accident. The second part assesses the benefits and limitations of qualitative research, and how it can be used in social science. Finally, the third part outlines methodological steps to analyse coping in Yoshida's narrative, while not neglecting the constraints of the approach.
\end{abstract}

\section{INTRODUCTION}

The concept of engineering in an extreme situation refers to engineering efforts that are carried out during a social emergency, in a highly uncertain context in which the available resources may be insufficient or inadequate (Guarnieri and Travadel, 2014). This was the situation that Tokyo Electric Power Company (TEPCO) employees found themselves in, during the accident at the Fukushima Dai Ichi nuclear power plant. The plant's on-site crisis centre and operational teams, who had become partly isolated from the outside word, had to cope with three reactors that were in danger of running out of control while at the same time being handicapped by a degraded infrastructure and the loss of electrical power. However, despite the difficult conditions, they were able to reorganise themselves and find innovative solutions to bring the situation back under control.

There is little information available that helps us to understand the conditions that determined how this extraordinary accident was managed. This makes the testimony of the plant's manager, Masao Yoshida, all the more important in understanding the situation as it was experienced by TEPCO workers (Afrouss and Portelli, 2016). 
Yoshida, together with the other principal actors in the disaster management, was summoned to testify to ICANPS, an ad hoc Committee established by the Japanese Government to investigate the accident. His testimony was made public on 11 September 2014, in the form of eleven documents written in Japanese, which are currently being translated into French (Guarnieri et al., 2015; Guarnieri et al., 2016.).

There are two reasons why it is important to study these transcripts in detail. First, it is the first time that the testimony of the Director of a nuclear power plant has been made available to both the scholarly community and the general public. Second, Yoshida, who was the Director of the on-site crisis centre, was the focal point for activity during the accident. In addition to coordinating employees in the field, he was in direct communication with TEPCO headquarters and the political authorities. He therefore had a broad overview of the roles of the different actors and a wide-ranging understanding of what was happening.

When putting the extreme situation into narrative, Yoshida describes how his teams, faced with a chaotic situation, managed to adapt and overcome unimaginable difficulties. The literature describes this mechanism as coping.

This article therefore proposes a method to analyse the relationship between coping and the extreme situation concepts. It begins with a presentation of the theoretical framework of coping and of the extreme situation, before going on to address the benefits and limitations of qualitative analyses. The third part suggests some avenues for research that emerge from the analysis of coping based on Yoshida's testimony.

\section{ADAPTATION STRATEGIES TO COPE WITH STRESSFUL SITUATIONS}

In an extreme situation, individuals are faced with conditions that threaten their physical integrity, their value system, or even civil society. They can become alienated, look for a solution to the problem, seek social recognition for the group, or withdraw from the group (Travadel and Guarnieri, 2015).

During the first days of the Fukushima disaster, workers were able to reinvent themselves and find innovative ways to regain control of the damaged reactors. Rather than passively abandon themselves to their fate, engineering teams sought creative solutions under Yoshida's effective management.

The literature terms the psychological and cognitive strategies that are put in place to adapt to stressful situations coping strategies. The next section defines this concept and presents its main components.

\subsection{Definitions of coping}

In the 1870s, Claude Bernard observed that living organisms had a range of ways to regulate their physicochemical properties and maintain the conditions necessary for life, even in disturbed conditions (Chrousos and Gold 1992). 
Cannon called this balance homeostasis and termed the disturbance stress. Inspired by the work of Bernard, he proposed the "fight or flight" model to explain animals' reactions to a threat, which implies heightened physical activity and emotions (Ibid.).

In 1956, Selye described the General Adaptation Syndrome (GAS). Triggered by various harmful agents, the GAS can be decomposed into three stages. The first is the alarm with a shock phase followed by an organism's response phase. In the second stage called resistance, resources are directed towards fighting the effects of the noxious agent. The final stage is either recovery or exhaustion, when the organism's resources are depleted and no further adaptation efforts are possible (Selye, 1956).

From another perspective, Freud looked at the ability to cope with stress. He was the first to postulate the existence of unconscious defence mechanisms, which may alter perceptions of the world in order to protect the individual from excessive anxiety, and the Ego from unacceptable ideas and emotions (Cramer, 1998).

Later literature classifies defence mechanisms according to their maturity. The most mature defences are those that have the least pathological impact on individuals, and are sometimes referred to as coping (Bruchon-Schweitzer, 2001).

Lazarus developed a model of the adaptation of individuals to stress, based on appraisals of the experienced situation and of the available resources. This concept, which he called coping, corresponds to "constantly changing cognitive and behavioral efforts to manage specific external and/or internal demands that are appraised as taxing or exceeding the resources of the person" (Lazarus and Folkman, 1984). Coping is seen as a process, rather than a personality trait. It includes all thoughts or acts regardless of their appropriateness and is unlike automatic adaptive behaviours, which do not require a special effort (Ibid.).

For some authors, defence mechanisms and coping are different, and can be distinguished by the presence of intention. The first are unconscious, automatic and dispositional, while the second corresponds to voluntary, intentional and conscious actions that are deliberately selected as a function of the context (Paulhan, 1992). For other scholars, they overlap or complement each other and are not necessarily opposed (Chabrol and Callahan, 2013).

Coping strategies are intended to deal with situations that are evaluated as stressful. The literature takes two approaches to stress. On the one hand, it corresponds to a stimulus that provokes a non-specific manifestation due to an aggressive agent. On the other hand, the transactional approach defines psychological stress as " $a$ particular relationship between the person and the environment that is appraised by the person as taxing or exceeding his or her resources and endangering his or her well-being" (Lazarus and Folkman, 1984).

From this perspective, stress is not reducible to its environmental dimension (i.e. the aggressive agent) or its individual dimension (i.e. available resources). The contribution of the second approach is that it marks a paradigm shift from behaviourism to a form of cognitive psychology. The individual is seen as having the cognitive ability to evaluate situations and choose the response that seems most appropriate. An individual's experience of stress is 
therefore a function of how the event is perceived, emotionally and cognitively. This process is called cognitive appraisal.

Lazarus and Folkman (1984) identify two forms of appraisal that occur simultaneously. The primary appraisal allows the individual to assess the effect of the situation on their well-being and how this effect will manifest. There are three options: irrelevant, benign/positive or stressful. Stressful events either instantly lead to loss or damage (to minimise the damage, to limit the threat or to take benefice from the situation), or they represent a threat or challenge. The secondary appraisal refers to the capacity to react to the situation and the effectiveness of the response.

In a stressful situation, individuals have several options open to them, "changing the situation, acceptance, escape, avoidance, seeking more information, seeking social support, or an impulsive action" (Paulhan, 1992). The choice of strategy is not arbitrary. It is the outcome of appraisals and reappraisals of the relationship between the individual and their environment, which might evolve over time (Lazarus and Folkman, 1984). This change can be attributed to the efforts made by the individual to act on their environment, or to adapt their representation of events. Changes can be completely independent of the individuals and stem exclusively from the external environment.

Several factors come into play in cognitive appraisal. Regardless of whether they are personal or contextual, they only make sense in the transactional relationship between the individual and the environment. Individual motivations and convictions, together with the characteristics of the situation (novelty, temporality, duration, information available), influence appraisal and adaptation efforts. The cultural context also plays a role, notably in the types of stressors one may encounter and in the appraisal. It also intervenes in the selection of coping strategies or the provision of institutional mechanisms to rely on (Aldwin, 2004).

Individual predispositions must also be taken into account. Personality traits such as extraversion, optimism and openness are positively correlated with the choice of strategy. A neurotic individual would tend to implement an avoidance strategy, while conscientiousness and agreeableness limit its use (Carver and Connor-Smith, 2010).

There are multiple classifications of coping strategies. For Lazarus and Folkman, the two principal functions are to act on the problem in order to change it, or to act on the person's emotions in order to reduce tension. These are termed problem-focused or emotion-focused strategies (Lazarus and Folkman, 1984). Another cross-cutting function, seeking social support, has been seen as a strategy in itself (Cobb, 1976). This can be directed at the problem (seeking assistance or advice) or the emotion (moral support, understanding). While the two forms have conceptual differences, clinical studies show that they often occur together when seeking social support (Carver et al., 1989). Individual attitudes can be considered to distinguish active, vigilant strategies from passive, avoidant ones (Paulhan, 1992). Finally, strategies differ considering whether they are cognitive or behavioural responses.

This literature review highlighted the diversity of work on coping strategies used by individuals who experience stress, and the factors that influence them. The approach theorised 
by Lazarus and his colleagues emphasizes the phenomenological aspect of stress, appraisal and coping and the importance of available resources. This concept has several features that are found in the conceptual framework of the extreme situation, as it was experienced by the workers who faced the Fukushima Dai Ichi accident.

\subsection{The relationship between Coping and the Extreme Situation}

The definition of the concept of the extreme situation refers to the conditions in which individuals or groups must intervene in a context that exceeds their capacity to act and might even threaten their very integrity.

In the case of Fukushima Dai Ichi, TEPCO teams found themselves in a hostile, changing and uncertain environment. The high levels of radiation made any kind of intervention onsite very difficult. Measurements of reactor parameters were unreliable and resources to face with reactor degradation and damage mitigation were extremely limited. The plant had been isolated by the earthquake and tsunami, which, in addition to making roads impassable, were the priority for emergency response teams.

The fact that it had become impossible to control the reactors translated into a resistance of reality for the individuals at Fukushima Dai Ichi. It made it mandatory for them to operate a shift in their values, representations and relationship with the world. It became necessary to change tack and modify the groups' objectives. This change had to incorporate both the group's new, shared representations and the expectations of the Japanese civil society (Guarneiri et al., 2015).

Recovery operations had to be carried out during an ongoing public emergency. Strategies had to be found that would bring the situation under control as quickly and effectively as possible as the public had very little sympathy - to the point that the actions that were taken could have been seen as threatening to the values of the whole society (Ibid.).

Fukushima Dai Ichi accident highlights the ability of the group to bounce back following a period of be-wilderment, numbness and helplessness. The deployment of strategies to enter into resilience can be considered as the final characteristic of an extreme situation (Guarnieri et al., 2016). Despite all of the obstacles in their path, workers were able to reorganise, innovate and adapt in order to come up with solutions to overcome the chaos.

Yoshida's testimony describes the reaction of the onsite crisis centre when the tsunami-the initial potentially destructive event-hit. The loss of alternative power resources that followed the event created an intensely stressful situation. "At that point, to be quite frank, I was devastated. Personally, I mean. I thought that we were facing a terrible situation" (Guarnieri et al., 2015, p. 106).

Many of the backup systems became inoperative and long-term reactor cooling could no longer be guaranteed. The available resources could not reduce or eliminate the source of stress. However, "it was no use complaining. Obviously, there was going to be a major accident and we had to prepare for it" (Ibid.). Despite the initial shock, Yoshida understood 
the urgency of the situation. The group had to find a response centred on the problem, which required controlling the reactors.

Some of his other cognitive reactions were more irrational and corresponded to a defensive attitude in the face of a stressful situation. "I believe that the explosion occurred when we were at around $500 \mathrm{kPa}$ at about $3 \mathrm{p.m}$. At that time, personally, the pressure made me uneasy. In reactor 1 , the pressure continued to rise, then fell back down to 500. But that didn't stop the number 500 making me uneasy. I know it's totally irrational, it was just very sensitive" (Ibid., p. 256). Yoshida then ordered a withdrawal of his teams in the field to protect them from exposition in case of an explosion in reactor 3.

The need for collective support is a recurring theme in Yoshida's testimony. In assuming a leadership role, he provided an outlet for tension, while channelling the group's energy towards solving the problem. "Everyone was in shock, frozen, couldn't think. So I got them all together to talk. I told them how very sorry I was to have them sent back into the field while it was still dangerous, I had made the wrong decision and I asked them to forgive me. I also told them that there was a high probability that the water injection had stopped, that we had to prepare for the injection of reactor 2, that if we didn't react there would be an even more catastrophic situation" (Ibid., p. 259).

These examples enable a comparison of the concepts of the extreme situation and coping. The transactional approach to stress/ coping suggests an analytical framework that can translate the mechanisms that come into play. Individuals find them-selves in a situation where their well-being, or physical, mental and social integrity is seriously threatened and where resources (notably physical and material) are manifestly lacking. They begin to look for proximal resources, while drawing upon the only social support available to them: the group.

In this scenario, resilience strategies correspond to the coping process, while public opinion influences the accept-ability of the situation at individual and group level. At Fukushima Dai Ichi, the only way to relieve stress was to act on the problem and limit the damage caused by the reactor explosions.

From this perspective, Yoshida's testimony is crucial as the manager recounts his perceptions of the accident, and how the group reacted to deal with extreme constraints. The comparison between the concepts of coping and the extreme situation found in Yoshida's narrative requires a qualitative approach, which is presented below.

\section{PRESENTATION OF THE METHODOLOGICAL FRAMEWORK OF OUR STUDY}

The use of qualitative methodologies in the humanities and social sciences boomed in the 1960s, notably in the English-speaking world, at a time when the quantitative analyses were dominant (Paillé, 2011). The benefits and limitations of qualitative analyses have been widely discussed in the literature.

\subsection{Benefits and limitations of Qualitative Methodology}


There is no clear definition of qualitative research. For many researchers, it is defined through the contrast with, or in reference to, quantitative research. However, the distinction is questionable and the two approaches can complement each other (Dumez, 2016).

However, it can be seen as a quest for meaning in the actions undertaking by observed actors. Qualitative analysis is "an ongoing, intuitive and natural intellectual effort that aims to find an appropriate re-arrangement of data in order to make it globally understandable, given a practical or theoretical problem that interests the researcher" (Paillé and Mucchielli, 2012).

Qualitative analysis is based primarily on the words, intentions, actions and interactions of actors. It can be carried out to identify mechanisms, establish typologies, or redefine concepts (Dumez, 2016). Some researchers associate it with four overlapping processes: data collection, preparation of the corpus, analysis, and interpretation (Sandelowski 1995). Preparation and analysis concern the re-organisation of data in such a way that the researcher is able to interpret them.

In the literature, data are often grouped into six categories: direct observations, interviews, notes taken by the researcher, documentation, participant observation and physical artefacts (Dumez, 2016). Although the collection of field data is a characteristic of the qualitative methods, it is not necessarily part of a textual or discourse analysis (Paillé, 2011).

The inherent role of imagination and creativity in discourse analysis means that its execution is closely related to the educational background and all the other elements that constitute the researcher's identity. A person's world view, education and theoretical foundations, among other factors, influence their analytical approach of data (Fallery and Rodhain, 2007).

Furthermore, Dumez (2016) notes three risks regarding qualitative (or comprehensive, in the sense that they aim at understanding actors, while taking quantitative factors into account) analysis. The first is to fail to show that actors actually act, instead focusing on structures, values or fuzzy concepts. The second is circularity-researchers who select a corpus of data that will provide support for their initial hypotheses. In this case, he may choose the elements that comfort his theory and reject the rest. Finally, two different explanations may lead to the same conclusion, considering the same first data. To avoid the risk of equifinality-being the risk of neglecting other plausible hypotheses - Dumez recommends "framing the puzzle" by specifying the research question in advance, processing the material independently from any theory, and systematically use counterfactual reasoning.

\subsection{Software-based Qualitative Analysis}

Researchers are increasingly using software packages for qualitative analysis (Computer Assisted Qualitative Data Analysis Software, CAQDAS), particularly for large corpus (Paillé, 2011). Software can save and organise data, and in some cases perform statistical analyses.

One package in particular, Nvivo, can carry out a thematic analysis of a dataset. Thematic analysis can be seen as a process that identifies, counts and qualifies the themes in a corpus with the eventual aim of content interpretation. 
The first version of Nvivo was published in 1999. Two approaches are possible: in the inductive approach themes emerge from the data; in the deductive approach the analyst decides the themes to be identified.

Nvivo offers a way to decontextualize meaning units that can be independently analysed, and then to group them into common themes; this step is called coding. This is achieved by associating keywords (nodes) with the data in the corpus. Nodes can be organised hierarchically or independently (Krief and Zardet, 2013). The categories that are obtained are then recontextualised to produce a coherent and meaningful result.

However, a limitation of the Nvivo analysis is that it is directly dependent on the coding scheme chosen by the researcher. By associating an item with a theme (rather than an idea), the analysis cannot accurately qualify a decontextualized item. The same theme can therefore contain different ideas and the underlying logic is not always obvious. Consequently, the transformation of the corpus into themes and their reconfiguration is transparent (Ibid.), which limits opportunities for cognitive interaction between different analysts.

\section{COPING IN THE EXTREME SITUATION: PROSPECTIVE FOR RESEARCH}

The testimony of Yoshida has many features that make it suitable for the study of how TEPCO teams coped following the nuclear accident. However, the method must acknowledge some biases introduced by this type of testimony.

\subsection{An analysis of Coping during an Extreme Situation}

We consider the hearings of Masao Yoshida as a narrativisation of the extreme situation, and a life narrative of the manager of the Fukushima Dai Ichi power plant (Afrouss and al., 2015; Afrouss and Portelli, 2016). This type of material is rarely used in management science (Sanséau, 2005).

Nevertheless, the biographical method, in the form of an access to reality (Ibid.) is a useful way to understand the meaning that the onsite actors gave to their actions. The life narrative is unusual as it explicitly refers to events in the narrator's life. The narrator transforms a set of memories into a coherent narrative according to an arrangement he finds appropriate.

This construction of sense and the assembly of past experience is considered by Ricœur as a form of emplotment (Ricœur, 1990), in which a collection of incoherent individual actions are presented as an intelligible, coherent and temporally-structured whole. The narrative, particularly when it is based on personal experience, makes it possible to generate a selfinterpretation, i.e. a manifestation of identity (Ricœur, 1995).

In practice, the life narrative depicts a character that is created by the speaker, who plays a role in a plot directed by the speaker, depending on the meaning he gives to his lived experience. The resulting story enables the teller to highlight on the upholding of the Self, while interactions with other actors, and the audience's reactions contribute to both the construction of the narrative and the speaker's character (Orofiamma, 2008). 
In telling his story, Yoshida presents himself in a context that involved various other actors (TEPCO employees and headquarters staff, firefighters, self-defence forces, political authorities). He ascribes to these different characters affects and moral judgements that enlighten their actions. Finally, it should be noted that the format for the hearings was determined by the Commissioners questions. Therefore, Yoshida's testimony followed overall a predefined chronological order. He instilled meaning in the by answering the questions or reorienting them to put more accuracy and light on the events.

However, an analysis of coping based on this material introduces certain biases. First, the data was not collected directly as the hearings were conducted by the ICANPS. Not all of the data that was obtained is relevant to our research and some of our questions remain unanswered. Second, the fact that the text has been translated from Japanese to French means that it may lose semantic and linguistic value. For example, certain expressions are modified to make them meaningful in French and cultural references may have been lost. The symbolism and social representations that are particular to the country are not always obvious to grasp as we are not Japanese studies scholars.

Actually, portraying a foreign individual based on his country's representations often leads to false constructions. This bias does not only refer to the Other, as it can also come from a member of the same community (Berting, 2001). The tendency to think of the Japanese as a community with a herd-like mentality where individuality is not valued continues to persist among some experts and is even fuelled by the Japanese themselves (Lozerand, 2014). Caution is therefore needed in order to avoid schematic shortcuts, by referring as precisely as possible to the scientific literature.

The emplotment of how the accident was managed allows Yoshida reconstruct his character as a member of a collective (Portelli and Guarnieri, 2016). This narrative process is not only a vector of argumentation and self-approval, but is a unique opportunity to understand the cognitive and behavioural development of an engineering team that was put to the test in an extreme situation as well. The analysis of this testimony therefore enables to highlight the mechanisms that were carried out to cope in a situation that was extremely threatening to individual integrity.

\subsection{Methodological steps and Research Perspectives}

The previous sections present a theoretical framework for the concept of coping, an epistemological framework for qualitative approaches, and the corpus that serves as the source of knowledge. We conclude by outlining the methodological steps and avenues for research into coping that are opened up by the analysis of Yoshida's narrative.

Our study can be decomposed into three chronological phases, identified by Wanlin (2007): pre-analysis, exploration of the material, and interpretation. Pre-analysis concerns the organisation of the material and an initial reading to take note of the corpus. It defines the scope of the investigation and sets out the hypotheses that would guide the research. In this case, the context is that of the extreme situation and the research question is formulated from the text. 
Our analytical framework raises questions about the relationship between coping and entry into resilience in an extreme situation, and helps us to determine the factors that influence the mechanisms that come into play in each process. Theoretically, the fact that workers felt abandoned by social actors (such as the government or TEPCO headquarters) contributed to their level of stress. As a matter of fact, social support and information about being valued and integrated in a group are factors that enhance the ability to deal with the stress (Carver et al., 1989). The integration to a collective, and the identification to this collective, favor collective coping of engagement and of elaboration of solutions coping. This relationship with otherness, whether intra- or extra-organisational, may be analysed in the scope of extreme situations. It allows understanding relationships with the institution or the group and their association with coping.

The pre-analysis also involves the de-contextualisation of the corpus. This requires the identification of the meaningful sections and categorising them under thematic headings that reflect the categories inherent in the research question and hypotheses: concerning (on one hand) the relationship with the others and (on the other hand) indicators of coping.

The second step is the exploration of the material and processing the results. This primarily concerns coding, which makes it possible to gather thematically-labelled elements into predefined categories. In a following step, the analytic framework is applied to selected segments of the narrative.

The third and final step involves inference or interpretation efforts. This must result in an original and objective interpretation of the corpus, based on the categories that were established during the exploration of the material. It also involves testing the validity of hypotheses by comparing them with the results.

To avoid any circularity bias, the approach should not be limited to a reading of the hearings based on an analytical framework that is shaped by the theoretical elements. Similarly, it is important to avoid using an existing coping typology for coding. A better approach is to start with the text and identify themes relating to stress or coping (using the Nvivo software package). Once these themes have been established, they can be grouped into categories that can be compared with the coping theory in order to verify its applicability in the context of the extreme situation at Fukushima Dai Ichi.

\section{CONCLUSION}

This article provides a new perspective on the concepts of coping and the extreme situation in the context of the Fukushima Dai Ichi accident.

Current theory suggests that there are potential similarities between the two concepts. We propose a method to investigate the relationship, based on the testimony of Masao Yoshida. With respect to coping, the avenues that this study opens up reflect our aim of understanding the actions taken by a group faced with a nuclear accident. We aim to clarify the stressors that affected workers and the psychosocial resources they mobilized to enter into resilience and overcome the crisis. 


\section{REFERENCES}

Afrouss, A., Portelli, A., Guarnieri, F., 2015. What can we learn about "engineering thinking in extreme sit-uations" from the testimony by the Fukushima Dai Ichi plant manager?, in: European Safety and Reliability Con-ference, Podofillini, L., Sudret, B., Stojadinović, B., Zio, E., Kröger, W. (Eds.), Safety and Reliability of Complex Engineered Systems: Proceedings of the 25th European Safety and Reliability Conference, ESREL 2015. CRC Press, Taylor \& Francis Group, a Balkema book, Zurich.

Afrouss, A., Portelli, A., 2016. La mise en récit de la situation extrême dans le témoignage de Masao Yoshida. in: Guarnieri, F., Travadel, S., Martin, C., Portelli, A., Afrouss, A., Przyswa E. (Eds.), L'accident de Fukushima Dai Ichi, Le Récit Du Directeur de La Centrale, Volume II, Seuls. Presses des Mines, Paris, pp. 53-68.

Aldwin, C.M., 2004. Culture, coping and resilience to stress, in: Ura, K., Galay, K. (Eds.), Proceedings of the First International Conference on Operationalization of Gross National Happiness. Thimphu, pp. 563-573.

Berting, J., 2001. Identités Collectives et Images de l'Autre: Les Pièges de la Pensée Collectiviste. Hermès 30, 41-58.

Bruchon-Schweitzer, M., 2001. Le coping et les stratégies d'ajustement face au stress. Recherche en soins infirmiers 68-83.

Carver, C.S., Connor-Smith, J., 2010. Personality and Coping. Annual Review of Psychology 61, 679-704.

Carver, C.S., Scheier, M.F., Weintraub, J.K., 1989. Assessing coping strategies: a theoretically based approach. Journal of personality and social psychology 56, 267-283.

Chabrol, H., Callahan, S., 2013. Mécanismes de défense et coping, Dunod. ed, Psycho Sup. Paris.

Chrousos, G.P., Gold, P.W., 1992. The concept of stress and stress system disorders. The Journal of the American Medical Association 267, 1244-1252.

Cobb, S., 1976. Social Support as a Moderator of Life Stress. Psychosomatic Medicine 38, 300-314.

Cramer, P., 1998. Coping and Defense Mechanisms: What's the Difference? Journal of Personality 66, $919-946$.

Dumez, H., 2016. Comprehensive Research: A methodological and epistemological introduction to qualitative research. Copenhagen Business School Press, Copenhagen.

Fallery, B., Rodhain, F., 2007. Quatre approches pour l'analyse de données textuelles: lexicale, linguistique, cognitive, thématique. Presented at the XVIème Conférence de l'Association Internationale de Management Stratégique AIMS, Montréal, Canada, pp. 116.

Guarnieri, F., Travadel, S., 2014. Engineering thinking in emergency situations: A new nuclear safety concept. Bulletin of the Atomic Scientists 70, 79-86. 
Guarnieri, F., Travadel, S., Martin, C., Portelli, A., Afrouss, A., 2015. L'accident de Fukushima Dai Ichi: le récit du directeur de la centrale. Volume I, L'anéantissement. Presses des Mines, Paris.

Guarnieri, F., Travadel, S., Martin, C., Portelli, A., Afrouss, A., Przyswa E., 2016. L'accident de Fukushima Dai Ichi : le récit du directeur de la centrale. Volume II : Seuls. Presses des Mines, Paris

Krief, N., Zardet, V., 2013. Analyse de données qualitatives et recherche-intervention. Recherches en Sciences de Gestion 2, 211-237

Lazarus, R.S., Folkman, S., 1984. Stress, appraisal, and coping, Nachdr. ed. Springer Publ, New York.

Lozerand, E., 2014. «Il n’y a pas d'individu au Japon.» Archéologie d'un stéréotype. Ebisu. Études japonaises 51 [en ligne].

Orofiamma, R., 2008. Les figures du sujet dans le récit de vie. En sociologie et en formation. Informations sociales $145,68-81$

Paillé, P., 2011. Les conditions de l'analyse qualitative. SociologieS [en ligne] 11.

Paillé, P., Mucchielli, A., 2012. L'analyse qualitative en sciences humaines et sociales. A. Colin, Paris.

Paulhan, I., 1992. Le concept de coping. L’année psychologique 92, 545-557.

Portelli and Guarnieri, 2016. Masao Yoshida par lui-même, in: Guarnieri, F., Travadel, S., Martin, C., Portelli, A., Afrouss, A., Przyswa E. (Eds.), L'accident de Fukushima Dai Ichi, Le Récit Du Directeur de La Centrale, Volume II, Seuls. Presses des Mines, Paris, pp. 4352.

Ricoeur, P., 1990. Time and narrative (Volume 1). University of Chicago Press, Chicago.

Ricoeur, P., 1995. Oneself as another. University of Chicago Press, Chicago.

Sandelowski, M., 1995. Qualitative analysis: What it is and how to begin. Research in nursing \& health $18,371-375$.

Sanséau, P.-Y., 2005. Les récits de vie comme stratégie d'accès au réel en sciences de gestion: pertinence, positionnement et perspectives d'analyse. Recherches qualitatives 25 , $33-57$.

Selye, H., 1956. The stress of life. McGraw-Hill, New York.

Travadel, S., Guarnieri, F., 2015. L'agir en situation extrême, in: Guarnieri, F., Travadel, S., Martin, C., Portelli, A., Afrouss, A. (Eds.), L'accident de Fukushima Dai Ichi, Le Récit Du Directeur de La Centrale, Volume I, L'anéantissement. Presses des Mines, Paris, pp. 283321.

Wanlin, P., 2007. L'analyse de contenu comme méthode d'analyse qualitative d'entretiens: une comparaison entre les traitements manuels et l'utilisation de logiciels. Recherches qualitatives 3, 243-272. 